\title{
TRAUMATIC DISLOCATION OF THE HIP WITH FRACTURE OF THE SHAFT OF THE IPSILATERAL FEMUR
}

\author{
Thomas G. Wadsworth, Liver pool, ENGland \\ From the Royal Liverpool Children's Hospital, Liverpool
}

Traumatic dislocation of the hip with a fracture of the shaft of the femur on the same side is such a rare injury that, although there are several reports of single patients, only two surgeons. Dehne and Immermann (1951), have reported treating a number of patients. Sir Astley Cooper in 1823 was the first to record the successful treatment of this condition. His patient, a boy of sixteen, had a fracture of the mid-shaft of the femur and a posterior dislocation of the hip. It was thought that the dislocation could not be reduced until the femoral fracture had united, and, five weeks after the injury, the dislocation was reduced in half an hour using pulley traction. Watson-Jones (1955) has stated recently that the fracture should first be reduced, and immobilised by internal fixation, before the hip is reduced.

Henry and Bayumi (1934) reported a patient aged sixty-four whom they first saw three weeks after injury and who had a fracture of the shaft of the femur and a dislocation of the hip: an attempt at closed reduction of the latter was unsuccessful and open reduction was performed. They found in the literature individual reports of fifteen other patients of whom seven had a successful closed reduction; one had an open reduction; in seven the dislocation was not reduced and in one reduction was doubtful. The youngest patient was eight and the eldest sixty-four years old.

Dehne and Immermann (1951) treated seven patients with this combined injury and gathered information on nine others treated by various surgeons. In only seven of these sixteen patients was the dislocation diagnosed soon after the injury. Closed reduction of the dislocation and open reduction of the fracture was successful in three, manipulation was successful in one with the help of skeletal traction through the tibial tubercle, two had open reduction of the dislocation and of the fracture, and the remaining patient had an open reduction of the fracture, but closed reduction of the dislocation failed (no further information was given). In the other nine patients the dislocation was recognised late. Open reduction of the dislocation was done in six, five of whom were left with marked stiffness in the hip; a sixth was treated after reduction by skeletal traction and was not allowed to bear weight for nearly three years and gained good hip movements; three patients had an arthrodesis of the hip, which was unsound in one. All these patients were adults, the youngest being twenty-one and the eldest forty-three years old.

Ingram and Turner (1954) reported a youth of seventeen who had bilateral dislocation of the hips with bilateral fractures of the femoral shafts, the reduction being done by skeletal traction through the greater trochanters. Wiltberger, Mitchell and Hedrick (1948) reported a man aged thirty-five who had a posterior dislocation of the hip and a fracture of the upper third of the shaft of the femur. They reduced the hip only after fixing a lever to the greater trochanter by two pins and applying skeletal traction through the tibial tubercle.

\section{CASE REPORT}

A healthy boy aged three years and three months was admitted to the Royal Liverpool Children's Hospital after having been knocked down in the street.

On examination his general condition was good. The left leg was held slightly medially rotated and adducted and the thigh was swollen. There was shortening of the leg. Movements at the left hip were restricted and painful, and crepitus could be detected in the thigh. There 
was no damage to important nerves or arteries. The pelvis was apparently intact, and there was no evidence of other injury.

Radiographs showed a transverse fracture of the middle third of the shaft of the femur with displacement and slight angulation. The hip was dislocated and the head of the femur was displaced upwards and backwards (Fig. 1).

Reduction of the fracture and the dislocation was done under general anaesthesia. The patient was supine and the pelvis was held by an assistant; the lower half of the thigh was grasped just above the knee and pulled, with the hip flexed to about 70 degrees. The greater trochanter was also pressed firmly downwards and forwards in the line of the femur and the thigh was adducted; the head of the femur was felt to slip quite easily into the acetabulum. The leg was immobilised in a Thomas's splint with skin traction for six weeks (Fig. 2), when the

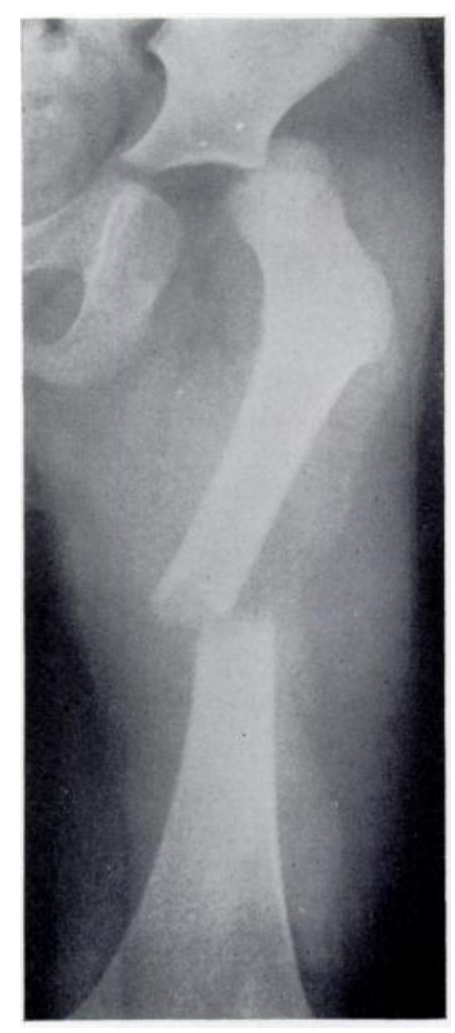

Fig. 1

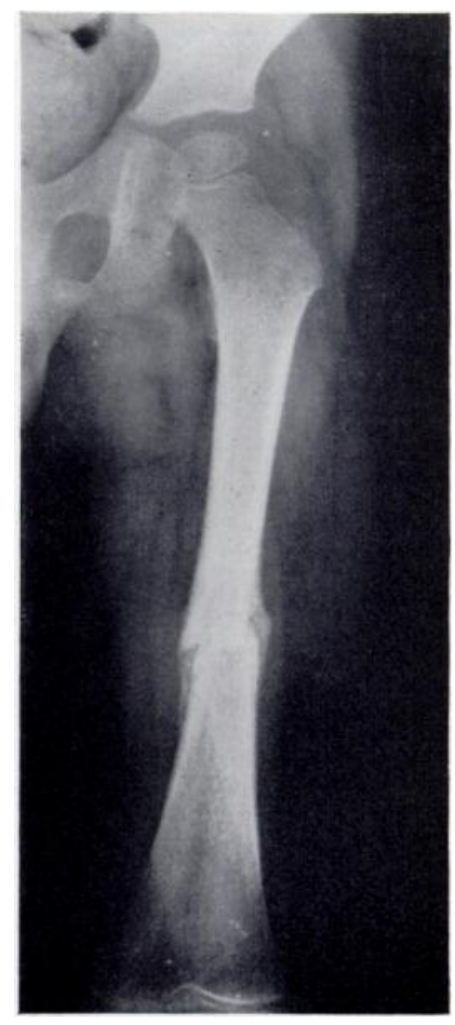

Fig. 2

Figure 1-Radiograph of a boy with a dislocated hip and a fractured shaft of femur on the same side. Figure 2-Six weeks after the injury the hip is satisfactory and the fracture is uniting.

child was allowed to move freely in bed for a further six weeks before starting to walk. Seven months after the accident he was walking normally. There was no shortening, the hip movements were normal and there was no evidence of avascular necrosis of the femoral head, or of subluxation, in the radiograph.

\section{DISCUSSION}

The rarity of the combination of fracture of the shaft of the femur and traumatic dislocation of the hip is indicated by the paucity of published cases. It is, however, important to remember that the two injuries can occur together, for in only seventeen out of forty-four patients was the dislocation diagnosed at the same time as the fracture. The unfortunate 
results of this have been pointed out by Dehne and Immermann. Thorough examination of the hip should be made in every patient with an injury to the leg and dislocation will be suspected when the greater trochanter is displaced and confirmed radiologically, but no reliance can be placed on an antero-posterior radiograph alone.

\section{SUMMARY}

1. A brief summary is given of the literature on patients with a dislocated hip and a fractured femur on the same side.

2. One further patient is reported, treated by closed reduction of the hip and the fracture.

3. A warning is given on the frequency with which the dislocation is not diagnosed in this double injury.

I wish to thank Professor Bryan McFarland for assisting me to publish this account.

\section{REFERENCES}

COOPER, Sir Astley (1823): A Treatise on Dislocations and on Fractures of Joints. Second edition, p. 62. London: The Author.

Dehne, E., and Immermann, E. W. (1951): Dislocation of the Hip Combined with Fracture of the Shaft of the Femur on the Same Side. Journal of Bone and Joint Surgery, 33-A, 731.

HenRy, A. K., and Bayumi, M. (1934): Fracture of the Femur with Luxation of the Ipsilateral Hip. British Journal of Surgery, 22, 204.

INGRam, A. J., and TURner, T. C. (1954): Bilateral Traumatic Posterior Dislocation of the Hip Complicated by Bilateral Fracture of the Femoral Shaft. Journal of Bone and Joint Surgery, 36-A, 1,249.

WATSON-JONES, Sir R. (1955): Fractures and Joint Injuries. Fourth edition, p. 678. Edinburgh and London: E. \& S. Livingstone Ltd.

Wiltberger, B. R., Mitchell, C. L., and Hedrick, D. W. (1948): Fracture of the Femoral Shaft Complicated by Hip Dislocation. Journal of Bone and Joint Surgery, 30-A, 225. 